LETTERS TO THE EDITOR

If you have a burning desire to respond to a paper published in Thorax, why not make use of our "rapid response" option? Log on to our website (www.thoraxjnl.com), find thle paper that interests you, and send your response via email by clicking on the "eletters" option in the box at the top right hand corner.

Providing it isn't libellous or obscene, it will be posted within seven days. You can retrieve it by clicking on "read eletters" on our homepage.

The editors will decide as before whether to also publish it in a future paper issue.

\section{NIV guidelines}

We congratulate the British Thoracic Society (BTS) Standards of Care Committee on their excellent guidelines on non-invasive ventilation (NIV) in acute respiratory failure. ${ }^{1}$ The guidelines are timely in that many district general hospitals (DGH) are setting up an NIV service. If our DGH experience is typical others may be surprised how quickly NIV takes off. Our DGH serves a catchment area of about 200000 people and use of NIV has increased from 51 patients in the year 1998/9 to 227 in $2000 / 1$. Whereas in $1998 / 978 \%$ of al the NIV treated patients were on the intensive care unit (ICU), in 2000/1 $71 \%$ were treated on wards. The keen involvement of the ICU anaesthetists has been pivotal in setting up the service.

We would query the statement that all patients started on NIV should be transferred to the care of a respiratory physician as soon as possible. In 2000/l 65 patients were treated on the ICU with NIV, many of these surgical patients being weaned off ventilators. Similarly, 28 "surgical" patients were treated on the wards with NIV. Should chest physicians really have to take over hospital care of all these patients?

The guidelines do not address the issue of the use of NIV in palliation of breathlessness. In acute exacerbations of chronic obstructive pulmonary disease (COPD) breathlessness settles more rapidly with NIV than with conventional treatment. ${ }^{2}$ In patients with severe respiratory distress who refused endotracheal intubation, anecdotally NIV was effective in reducing breathlessness. ${ }^{3}$ It is not surprising that the role of NIV in treating breathlessness is unclear, given the uncertainty over the efficacy of other interventions which have been available for many years such as oxygen, benzodiazepines, morphine, or breathing exercises. We have found NIV useful in reducing dyspnoea in some patients with end stage respiratory disease, and agree with the guidelines that it is vital it be clearly documented whether NIV is being used with palliative or curative intent, and whether or not to proceed to invasive ventilation.

\section{D Shee, M Green} Queen Mary's Hospital, Sidcup, Kent DA14 6LT, UK

\section{References}

1 British Thoracic Society Standards of Care Committee. Non-invasive ventilation in acute respiratory failure. Thorax 2002;57:192211.

2 Plant PK, Owen JL, Elliott MW. Early use of non-invasive ventilation for acute exacerbations of chronic obstructive pulmonary disease on general respiratory wards: a multi-centre randomised controlled trial. Lancet 2000;355:1931-5.

3 Meduri GU, Fox RC, Abou-Shala N, et al. Non-invasive mechanical ventilation via face mask in patients with acute respiratory failure who refused endotracheal intubation. Crit Care Med 1994;22:1584-90.

We read the BTS guideline on non-invasive ventilation (NIV) in acute respiratory failure with great interest. The paper is an excellent summary and a very good reference for a number of situations related to this nove approach. We have, however, some questions which we wish to raise.

Nowadays it is widely accepted that NIV is superior to both invasive mechanical ventilation and standard medical treatment in selected patients with exacerbations of hypercapnic chronic obstructive pulmonary disease (COPD). The skills required for NIV are easily learnt and the equipment required is relatively inexpensive. The complication rate is very low compared with invasive ventilation, and it has been shown by Plant et $a^{2}$ that NIV is cheaper with a lower mortality rate than standard medical treatment in patients with COPD. The use of NIV outside the ICU and by physicians, nurses, or respiratory care practitioners is also beneficial, allowing early intervention to prevent further respiratory deterioration, access to respiratory support for patients who would not otherwise be admitted to the ICU, and the provision of support in a less intimidating setting. Success rates of NIV in such patients can be higher than $90 \%,{ }^{3}$ depending on appropriate selection of patients, close monitoring in the first 4-6 hours, and the experience of the staff. However, according to the BTS guideline, ${ }^{1}$ NIV does not appear to be a suitable treatment modality for low income countries because of the limited availability of ICU facilities. Although there is no doubt that the best settings in which to use NIV are those stated in the guideline, it is not always possible for a low income country to set up a countrywide ICU service. The number of patients with acute COPD exacerbations is no lower than in developed countries, so shouldn't we use NIV in selected COPD patients with acute exacerbations even if there is no ICU service in the near area? Would it be ethical not to use this simple and inexpensive device in those selected patients if you have a well trained staff but no ICU service?

O Dikensoy, A Filiz, E Ekinci

Department of Pulmonary Diseases, Gaziantep University, School of Medicine, Gaziantep 27070 Turkey; dikensoy@yahoo.com

\section{References}

1 British Thoracic Society Standards of Care Committee. Non-invasive ventilation in acute respiratory failure. Thorax 2002;57:192211

2 Plant PK, Owen JL, Elliott MW. Early use of non-invasive ventilation for acute exacerbations of chronic obstructive pulmonary disease on general respiratory wards: a multicentre randomised controlled trial. Lancet 2000;355: 1931-5.

3 Kramer N, Meyer TJ, Meharg J, et al. Randomized prospective trial of noninvasive positive pressure ventilation in acute respiratory failure. Am J Respir Crit Care Med 1995;151:1799-806

\section{Author's reply}

In response to the criticism that it is unnecessary to transfer all patients on non-invasive ventilation (NIV) to the care of a respiratory physician as soon as possible, these are guidelines not rules. I am unhappy with the suggestion that NIV should be managed by surgeons, although clearly there may be hospitals where the surgeons have sufficient training and experience in NIV for this to be acceptable. I agree that NIV can be used to palliate breathlessness, but I did not specifically address this area of use in the guideline.

In answer to the question as to whether it would be ethical to use NIV if there is no intensive care service available, I agree that in special circumstances this would be entirely reasonable.

W J M Kinnear

Department of Respiratory Medicine, Queen's Medical Centre, Nottingham NG7 2UH, UK; William.Kinnear@mail.qmcuh-tr.trent.nhs.uk

\section{CORRECTION}

\section{GM-CSF therapy in pulmonary alveolar proteinosis}

In the letter by $M$ G de Vega et al entitled "GM-CSF therapy in pulmonary alveolar proteinosis" which appeared on page 837 of the September issue of Thorax (Volume 57, No 9), the name of Dr A Romero was inadvertently omitted as the first author. The authors of the letter should have been: A Romero, M G de Vega, A Sánchez-Palencia, A Ramírez and $S$ Cervera. The publishers apologise for this error. 